\title{
From High-Temperature Orientationally Disordered Mixed Crystals to Low-Temperature Complex Formation in the Two-Component System $\left(\mathrm{CH}_{3}\right)_{3} \mathrm{CBr}+\mathrm{Cl}_{3} \mathrm{CBr}$
}

\author{
María Barrio, $^{\dagger}$ Philippe Negrier, ${ }^{\ddagger}$ Josep Ll. Tamarit, $^{*,+}$ and Denise Mondieig ${ }^{\ddagger}$ \\ ${ }^{\dagger}$ Grup de Caracterització de Materials, Departament de Física i Enginyeria Nuclear, ETSEIB, \\ Universitat Politècnica de Catalunya, Diagonal, 64708028 barcelona, Catalonia, Spain \\ ${ }^{\ddagger}$ Centre de Physique Moléculaire, Optique et Hertzienne, UMR 5798 au CNRS Université Bordeaux I, 351, \\ cours de la Libération, 33405 Talence Cedex, France
}

\begin{abstract}
The phase diagram of the two component systems $\left(\mathrm{CH}_{3}\right)_{3}$ $\mathrm{CBr}+\mathrm{Cl}_{3} \mathrm{CBr}$ has been experimentally determined by means of differ ential scanning calorimetry and $\mathrm{X}$ ray powder diffraction techniques from the low temperature ordered phases to the liquid state. Before melting, both components have the same orientationally disordered (OD) face centered cubic (FCC) and rhombohedral (R) phases, and the two phase equilibria $[\mathrm{FCC}+\mathrm{L}]$ and $[\mathrm{R}+\mathrm{FCC}]$ are accounted for by means of the existence of an isomorphic relationship between the OD phases of pure compounds. The thermodynamic assessment of such equilibria enables us to get the excess properties of the involved OD phases and to rationalize the existence of a maximum and a minimum in the $[\mathrm{R}+\mathrm{FCC}]$ equilibrium on the basis of the contribution of the entropic term in the excess Gibbs energy function. At low temperature, two complexes, $\left(\mathrm{CH}_{3}\right)_{3} \mathrm{CBr}: \mathrm{Cl}_{3} \mathrm{CBr}(1: 1)$ and $\left(\mathrm{CH}_{3}\right)_{3} \mathrm{CBr}: 2 \mathrm{Cl}_{3} \mathrm{CBr}(1: 2)$, appear. The structures of $1: 1$ and $1: 2$ complexes have been determined to be monoclinic $\left(P 2_{1} / n, c\right.$, $Z=4)$ and hexagonal $\left(\mathrm{P}_{3}, \mathrm{Z}=6\right)$. Within both "ordered" structures, the $\mathrm{Cl}_{3} \mathrm{CBr}$ entities of the asymmetric unit were found to be disordered so that sites have fractional occupancies of 0.75 and 0.25 for $\mathrm{Cl}$ and $\mathrm{Br}$ atoms, in the same way that it occurs for the low temperature monoclinic $(\mathrm{C} 2 / \mathrm{c}, \mathrm{Z}=32)$ phase of $\mathrm{Cl}_{3} \mathrm{CBr}$. Finally, the existence of complexes is connected with the special intermolecular interactions appearing between a methyl group and a halogen, as previously inferred by Calvet et al. [T. Calvet et al. J. Chem. Phys. 1999, 110, 4841].
\end{abstract}

\section{INTRODUCTION}

Simple tetrahedral methylhalogenomethane (MHM) com pounds, $\left(\mathrm{CH}_{3}\right)_{4}(m+n) \mathrm{CX}_{m} \mathrm{Y}_{n}(\mathrm{X}, \mathrm{Y}=\mathrm{F}, \mathrm{Cl}, \mathrm{Br}, \mathrm{I}, n, m=0, \ldots$ 4 ), have stimulated a large number of experimental studies as well as have been the object of many theoretical works through molecular dynamics simulations to rationalize the intermolecular interactions and the nature of the orientationally disordered (OD) or plastic phases appearing within the rich polymorphic behavior of such compounds. ${ }^{1}{ }^{34}$ It should be emphasized that this set of compounds constitutes a remarkable case study because these molecules have very close size and a limited kind of intermolecular interactions. These characteristics make sys tematic studies and comparisons possible.

One of the most outstanding characteristics of the MHM compounds is their pseudospherical shape due to the tetrahedral molecular symmetry and similar size of the halogen or methyl group attached to the carbon center. Such a property is the most general of materials displaying an OD phase. ${ }^{35,36}$ Upon increas ing temperature from a positional and orientational long range ordered crystal structure, various phase transitions may occur associated with the reduction of some type of order. In the case of pseudospherical shaped molecules, the orientational order is lost first, giving a phase where molecules are able to reorient on their lattice sites, a phase commonly known as plastic phase, a term which is also used to describe the high temperature phase existing just before the liquid state. ${ }^{36}$ In spite of the similarity in size and intermolecular interactions, the polymorphic behav ior within the realm of MHM compounds at normal pressure (i.e., in equilibrium with its vapor pressure), as well as at high pressure, is known to be quite different, a fingerprint that small differences of size and intermolecular interactions finely tune the thermodynamic functions accounting for the stability of the phases. $^{3} 5,1618,22 \quad 34,37,38$ The stability of the phases can be revealed not only by means of the study of pure compounds, as a function of temperature and pressure, but also by the determi nation of the phase diagram between two homologous com pounds. ${ }^{31,33,34,39}{ }^{42}$ With the last procedure, the formation of mixed crystals provides information on the thermodynamic mixing properties, thus on the interactions between their mo lecular units and, in some cases, on the intrinsic polymorphic behavior of the pure compounds. ${ }^{40,43}$

The case of MHM compounds, the issue of this article, is relevant in two intrinsically linked respects. On one hand, several 
molecular dynamics simulation works have proved that, for $\left(\mathrm{CH}_{3}\right)_{4}{ }_{n} \mathrm{CCl}_{n}(n=0, \ldots, 4)$ compounds, there is a neat charge transfer from the methyl group to the chlorine centers, in such a way that the methyl group turns slightly positive whereas the chlorine atom turns negative, this behavior being more marked for polar molecules $(n=1,2,3)$ than for nonpolar ones $(n=$ $0,4) .{ }^{8}{ }^{11}$ As a consequence, it is highlighted that the dipole moments of the liquid phases are considerably higher than those calculated for the gas phase due to a strong dipole induction exceeding even by about $30 \%$ what was estimated until now. ${ }^{10}$ These molecular dynamics calculations make then evident the intricate interaction when methyl groups and chlorine atoms are put together.

The second relevant aspect concerns experimental evidence related to two component phase diagrams sharing molecules in which methyl and halogen entities are involved. Some years ago Calvet et al. ${ }^{44}$ reported on several binary phase diagrams composed of chemically homologous molecules, in particular, 2 methylnaphthalene +2 chloronaphthalene and 2 methylnaph thalene +2 bromonaphthalene, as exceptional cases in which the formation of mixed crystals goes together with the existence of a solid-liquid two phase equilibrium with a maximum. The authors argued through a careful thermodynamic assessment of phase diagrams that the consequence of such exceptionality is the net attraction between methyl and halogen $(\mathrm{Cl}$ or $\mathrm{Br}$ ) which gives rise to negative values of the excess thermodynamic properties of the mixed crystals. The work nicely adds a statistical study on methyl-methyl, halogen-halogen, and halogen-methyl inter molecular contacts among crystal structures collected in the Cambridge Structural Database. The conclusion of this extended analysis is the evidence of a net attraction between the methyl and halogen $(\mathrm{X})$, which the authors wrote in the form: $\left(-\mathrm{CH}_{3} \cdots \mathrm{X}-\right)>1 / 2\left\{(-\mathrm{X} \cdot \cdots \mathrm{X}-)+\left(-\mathrm{CH}_{3} \cdots-\mathrm{CH}_{3}\right)\right\}$. This means that the crossed ("mixed", according to the author's words) interaction between methyl and halogen is stronger than the average ("unmixed") of those due to methyl-methyl and halogen-halogen.

It should be noticed that within a mixed crystal the attraction between molecules A and B is generally weaker that the mean of the attraction between $\mathrm{A}$ and $\mathrm{A}$ molecules in the solid state of compound $\mathrm{A}$ and the attraction between $\mathrm{B}$ and $\mathrm{B}$ in $\mathrm{B} .{ }^{45}$ This common behavior gives rise to a net repulsion which translates to positive values of the energy of mixing generally associated to the effect of the geometric mismatch related to the difference in shape and size of the molecules A and B involved, although there is not a rule to exactly quantify such an effect. In the case of orientationally disordered phases, as for the high temperature phases of MHM compounds dealt with in this article, the mismatch effect is partially "dissolved" due to the apparent spherical shape of the molecules within the high symmetry lattice in which molecules reorient, and only the size effect remains. ${ }^{46,47}$

Some examples of two component systems showing a mini mum and a maximum in the two phase equilibria sharing $O D$ phases have been recently published (Figure 1). They involved MHM derivatives and thus bring into play crossed interactions between methyl and halogen. ${ }^{40,41}$ Unfortunately, the low tem perature region of these phase diagrams has not been reported, and thus the influence of such intermolecular interaction within the fully ordered state is unknown.

Here we report on results on a two component system between 2 bromo 2 methyl propane $\left(\left(\mathrm{CH}_{3}\right)_{3} \mathrm{CBr}\right)$ and bromo trichloromethane $\left(\mathrm{Cl}_{3} \mathrm{CBr}\right)$ from low temperature ordered phases
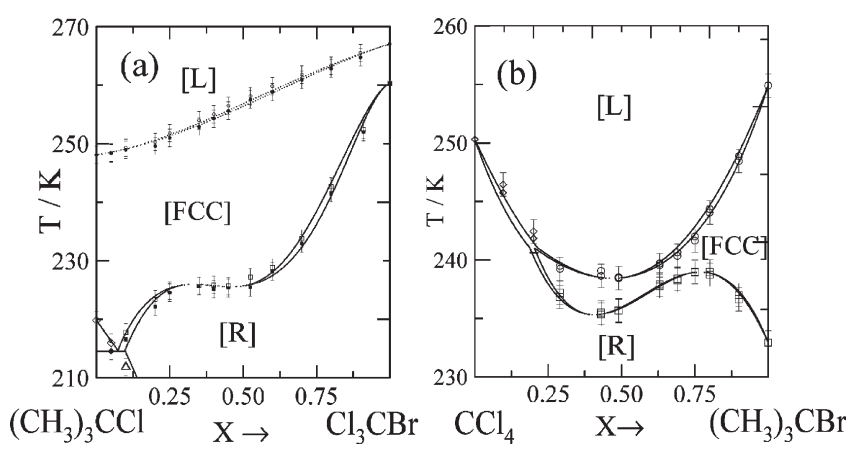

Figure 1. Two component phase diagrams sharing methylhalogeno methane derivatives showing maxima and minima in the $[\mathrm{R}+\mathrm{FCC}]$ two phase equilibria. ${ }^{41,40}$.

Table 1. Temperatures and Enthalpy and Entropy Changes Associated with the Phase Transitions of $\left(\mathrm{CH}_{3}\right)_{3} \mathrm{CBr}$ and $\mathrm{Cl}_{3} \mathrm{CBr}$ Used in This Work and Previously Reported ${ }^{a}$

\begin{tabular}{|c|c|c|c|c|c|}
\hline & transition & $T / \mathrm{K}$ & $\begin{array}{c}\Delta H / \mathrm{kJ} \\
\mathrm{mol}^{1}\end{array}$ & $\begin{array}{c}\Delta S / \\
\mathrm{J} \cdot \mathrm{mol}^{1} \\
\mathrm{~K}^{1}\end{array}$ & reference \\
\hline \multirow[t]{8}{*}{$\left(\mathrm{CH}_{3}\right)_{3} \mathrm{CBr}$} & \multirow[t]{3}{*}{$\mathrm{O} \rightarrow \mathrm{R}$} & $209.0 \pm 1.0$ & \multirow[t]{3}{*}{$5.90 \pm 0.17$} & $28.23 \pm 0.80$ & 32 \\
\hline & & $209.3 \pm 0.5$ & & $27.95 \pm 0.48$ & 48 \\
\hline & & 208.0 & & 27.15 & 5 \\
\hline & \multirow[t]{3}{*}{$\mathrm{R} \rightarrow \mathrm{FCC}$} & $232.9 \pm 1.0$ & $0.96 \pm 0.04$ & $4.12 \pm 0.15$ & 32 \\
\hline & & $231.8 \pm 0.3$ & 0.97 & $4.14 \pm 0.04$ & 48 \\
\hline & & 233.0 & 1.05 & 4.49 & 5 \\
\hline & \multirow[t]{2}{*}{$\mathrm{FCC} \rightarrow \mathrm{L}$} & $254.9 \pm 1.1$ & $1.72 \pm 0.10$ & $6.77 \pm 0.38$ & 32 \\
\hline & & 255.5 & 1.966 & 7.69 & 5 \\
\hline \multirow[t]{6}{*}{$\mathrm{Cl}_{3} \mathrm{CBr}$} & \multirow[t]{2}{*}{$\mathrm{M} \rightarrow \mathrm{R}$} & 238.1 & 4.58 & 19.23 & 38 \\
\hline & & 238.19 & 4.618 & 19.40 & 26 \\
\hline & \multirow[t]{2}{*}{$\mathrm{R} \rightarrow \mathrm{FCC}$} & 260.3 & 0.52 & 1.98 & 38 \\
\hline & & 259.34 & 0.527 & 2.03 & 26 \\
\hline & \multirow[t]{2}{*}{$\mathrm{FCC} \rightarrow \mathrm{L}$} & 267.1 & 2.03 & 7.61 & 38 \\
\hline & & 267.9 & 2.032 & 7.59 & 26 \\
\hline
\end{tabular}

${ }^{a} \mathrm{O}$ refers to the low temperature orthorhombic $\left(\mathrm{Pmn} 2_{1}\right)$ phase of $\left(\mathrm{CH}_{3}\right)_{3} \mathrm{CBr}, \mathrm{M}$ to the low temperature monoclinic $(\mathrm{C} 2 / \mathrm{c})$ phase of $\mathrm{Cl}_{3} \mathrm{CBr}$, and $\mathrm{R}$ and $\mathrm{FCC}$ to the orientationally disordered rhombohedral and face centered cubic phases.

up to the normal liquid range. It should be kept in mind that the molecular volume difference between these compounds is no more that $2.5 \%$, so the influence of the size in the mixing pro perties can be neglected.

The polymorphic behavior of these compounds, both formed by molecules with $C_{3 v}$ symmetry, has been recently reported, and it is outlined in Table 1 . As for the polymorphism of $\mathrm{Cl}_{3} \mathrm{CBr}$ at normal pressure, the lattice symmetry of the low temperature ordered phase is $C 2 / c(Z=32),{ }^{27,38}$ i.e., isostructural with the low temperature phases of the subset of the MHM compounds $\mathrm{Cl}_{n} \mathrm{CBr}_{4}{ }_{n}, n=0, \ldots, 4{ }^{49}$ It should be mentioned that, according to this isostructural character, in the low temperature phase of compounds in which two different halogen atoms are present $(n=2,3)$ the molecules are disordered so that sites have frac tional occupancies of 0.75 and 0.25 , for $\mathrm{Cl}_{3} \mathrm{CBr}$, and of 0.50 , for $\mathrm{Cl}_{2} \mathrm{CBr}_{2}$, for each of the $\mathrm{Cl}$ and $\mathrm{Br}$ atoms, respectively. $\mathrm{On}$ heating from the monoclinic low temperature phase $\mathrm{Cl}_{3} \mathrm{CBr}$ transforms at $238 \mathrm{~K}$ to an $\mathrm{OD}$ rhombohedral (R) phase, and at 
$260 \mathrm{~K}$ an OD FCC phase appears, which is stable up to the melting point at $267 \mathrm{~K}$.

As far as $\left(\mathrm{CH}_{3}\right)_{3} \mathrm{CBr}$ is concerned, the long time unknown structure of the low temperature phase has been recently deter mined as orthorhombic (O) Pmn $2_{1}$, and thus the polymorphism has been perfectly established at normal and high pressure. ${ }^{29,32}$ On heating from the low temperature ordered phase $\mathrm{O}$, it trans forms at $209 \mathrm{~K}$ to an OD R phase which, on further heating, changes at $233 \mathrm{~K}$ to an OD FCC phase, the phase which melts at $255 \mathrm{~K}$.

The similarity between the lattice parameters of both OD $\mathrm{R}$ and $\mathrm{FCC}$ phases for $\left(\mathrm{CH}_{3}\right)_{3} \mathrm{CBr}$ and $\mathrm{Cl}_{3} \mathrm{CBr}$ as well as the close size of both molecules suggest the possibility of continuous formation of R and FCC mixed crystals and, according to the previous reports ${ }^{40,41,44}$ on the intermolecular interactions be tween methyl and halogen, the possibility of the existence of singularities (maxima or minima) in the two phase equilibria of the phase diagram. In addition, the question whether such a recognized special interaction between methyl and halogen propagates along the low temperature region can be scrutinized.

This article is organized as follows. In section 2 we provide the experimental details concerning calorimetric and $\mathrm{X}$ ray diffrac tion techniques conducted for the determination of the two com ponent phase diagram. In section 3 the experimental results and the assessment of the phase diagram to derive the excess prop erties are presented. Section 4 is devoted to the discussion of results, and finally, we summarize the main conclusions in section 5 .

\section{EXPERIMENTAL SECTION}

2.1. Materials. The chemicals $\left(\mathrm{CH}_{3}\right)_{3} \mathrm{CBr}$ (Fluka, purity better than 98\%) and $\mathrm{Cl}_{3} \mathrm{CBr}$ (Across, purity higher than 99\%) were used as purchased without further purification since the measured melting and transition thermodynamic values agreed well with the ones reported earlier. ${ }^{32,38}$ Binary mixtures were prepared at room temperature, i.e., in the liquid state, by mixing the materials in the desired proportions.

2.2. Thermal Analysis. A Perkin-Elmer DSC 7 differential scanning calorimeter equipped with a homemade low tempera ture adapter was used. Heating and cooling rates of $2 \mathrm{~K} \mathrm{~min}{ }^{1}$ and sample masses around $15 \mathrm{mg}$ gathered in Perkin Elmer high pressure stainless steel pans were used.

2.3. Excess Enthalpy of the Liquid Phase. The excess enthalpy in the liquid state was determined at $295 \mathrm{~K}$ by means of a com mercial Biocalorimetre BCP from Electronique Arion for which a homemade mixing cell device was manufactured. The calorimeter and the procedure have been carefully described elsewhere. ${ }^{50}$

2.4. X-ray Powder Diffraction. X ray powder diffraction data were recorded by means of a horizontally mounted INEL cylind rical position sensitive detector (CPS 120) using Debye-Scherrer geometry (angular step ca. $0.029^{\circ} 2 \theta$ over a $2 \theta$ range from 2 to $115^{\circ}$ ) and equipped with a liquid nitrogen 600 series Cryostream Cooler from Oxford Cryosystems with a temperature accuracy of $0.1 \mathrm{~K}$ and similar for fluctuations. Monochromatic $\mathrm{Cu} \mathrm{K \alpha}_{1}(\lambda=$ $1.5406 \AA$ ) radiation powered with $1.0 \mathrm{~kW}(40 \mathrm{kV}$ and $25 \mathrm{~mA})$ was selected. External calibration using the $\mathrm{Na}_{2} \mathrm{Ca}_{3} \mathrm{Al}_{2} \mathrm{~F}_{4}$ cubic phase mixed with Silver Behenate was performed by means of cubic spline fittings. The peak positions were determined by pseudo Voigt fittings. Crystal structures have been resolved by using the modules Powder Indexing for cell searching, the Powder Refinement for full profile determination after pseudo Voigt fittings, ${ }_{51}^{51}$ and the module Powder Solve $^{52}$ of the Material Studio application. ${ }^{53}$

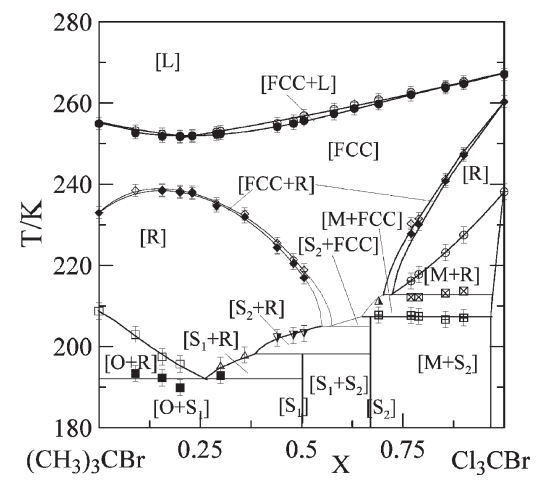

Figure 2. Binary phase diagram of $\left(\mathrm{CH}_{3}\right)_{3} \mathrm{CBr}+\mathrm{Cl}_{3} \mathrm{CBr}$. Symbols show the temperatures detected by means of thermal analysis. The intricate behavior around the composition domains where complexes appear was established by means of $\mathrm{X}$ ray powder diffraction as a function of temperature (see text and Figure 4).

Liquid samples were placed at room temperature into $0.3 \mathrm{~mm}$ diameter Lindemann capillaries. During data collection, capil laries were rotated perpendicularly to the $\mathrm{X}$ ray beam direction to minimize possible effects of preferred orientations.

\section{RESULTS}

3.1. Experimental Phase Diagram. By combining differen tial scanning calorimetry and $\mathrm{X}$ ray powder diffraction, the transition temperatures as a function of composition can be determined to build up the phase diagram. Figure 2 shows the phase diagram from $180 \mathrm{~K}$ up to the liquid state. Below $180 \mathrm{~K}$ and until ca. $100 \mathrm{~K}$, no phase transitions for mixed crystals or for pure compounds appeared.

The structural phase changes of the samples were detected either by thermal analysis or by the analysis of short time acquisi tion $\mathrm{X}$ ray patterns as a function of temperature, while long time acquisition patterns were collected at constant temperature (see section 3.3) in the low temperature domain to characterize the formation of complexes. The aim of this study is 3 fold: (i) to limit, as far as possible, the low temperature miscibility regions for the involved phases; (ii) to establish the existence of $\mathrm{R}$ and FCC mixed crystals vs mole fraction; and (iii) to characterize the structure of low temperature complexes obtained by means of long annealing times.

The samples were slowly cooled until ca. $100 \mathrm{~K}$ and heated again at $180 \mathrm{~K}$ where they were annealed and controlled by in situ $\mathrm{X}$ ray diffraction measurements. After the intensity of the main reflections was determined to be constant as a function of time (no less than ca. $12 \mathrm{~h}$ ), the samples were heated by steps of no more than $5 \mathrm{~K}$, and patterns were collected to determine the equilibrium phases. Such a procedure enabled us to establish the phase transitions as well as the stability domains, especially around the mole fractions close to those where complexes are formed.

The binary phase diagram thus obtained is shown in Figure 2. The main characteristics of the phase diagram may be described as follows. The existence of OD FCC mixed crystals for the whole concentration range can be inferred from the continuous varia tion of the melting temperatures and the enthalpy change at the melting transition (Figure 3) as well as the continuous variation of the cubic lattice parameter as a function of the mole frac tion (see section 3.2 ), i.e., all the requirements needed for the 


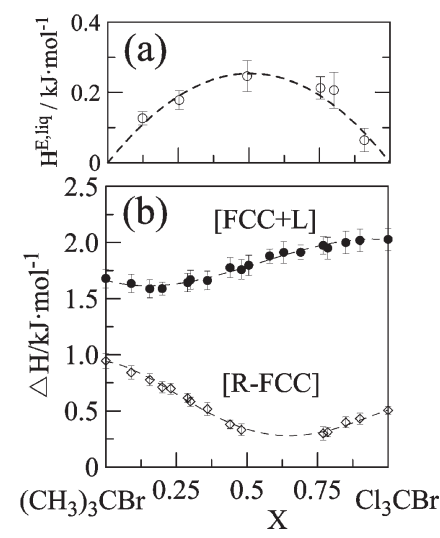

Figure 3. Experimental excess enthalpy of the liquid state (a) and enthalpies of melting of OD FCC phase (circles) and enthalpies of R to FCC (diamonds) transition (b) as a function of the mole fraction.

existence of an isomorphism relationship between the FCC phases of pure compounds. ${ }^{45}$ As for the OD R mixed crystals, the $[\mathrm{R}+$ FCC] two phase equilibrium interferes with low temperature two phase equilibria in which ordered phases are involved, casting thus doubts concerning the existence of an isomorphism relationship between the $\mathrm{R}$ phases of pure components. Such a query is solved by the continuity as a function of mole frac tion of (i) the experimental enthalpy change of the R to FCC (Figure 3b), (ii) the $\mathrm{R}$ lattice parameters (see section 3.2), and (iii) the existence of one Gibbs function for the $\mathrm{R}$ phase for a complete thermodynamic description of the $[\mathrm{R}+\mathrm{FCC}]$ two phase equilibrium (see section 3.4).

As far as the low temperature region of the binary phase diagram is concerned, it can be seen that two new intermediate phases, i.e., complexes, appear around the molar ratios 1:1 $\left(\mathrm{S}_{1}\right)$ and 1:2 $\left(\mathrm{S}_{2}\right)\left(\left(\mathrm{CH}_{3}\right)_{3} \mathrm{CBr}: \mathrm{Cl}_{3} \mathrm{CBr}\right)$ giving rise to a set of three phase invariants. More specifically, there are two eutectoid invariants, $\left[\mathrm{S}_{2}+\mathrm{R}+\mathrm{FCC}\right]$ at $205.0 \pm 3.0 \mathrm{~K}$ and $\left[\mathrm{S}_{1}+\mathrm{O}+\mathrm{R}\right]$ at $192.0 \pm 1.6 \mathrm{~K}$; two peritectoid invariants, $\left[\mathrm{S}_{2}+\mathrm{M}+\mathrm{FCC}\right]$ at $207.3 \pm 1.5 \mathrm{~K}$ and $\left[S_{2}+S_{1}+\mathrm{R}\right]$ at $198.2 \pm 3.0 \mathrm{~K}$; and one metatectoid, $[\mathrm{M}+\mathrm{R}+\mathrm{FCC}]$ at $212.8 \pm 1.7 \mathrm{~K}$. Some of the mentioned invariants are clearly visible by means of thermal measurements, but $\mathrm{X}$ ray diffraction as a function of temperature was used as previously described to elucidate the intricate sequence of phases. As examples of the used procedure, Figure 4 shows the structural changes when temperature is increased for samples with mole fractions of 0.54 and 0.75 .

The enthalpy changes associated with the melting of the OD FCC mixed crystals as well as with the R to FCC phase transition, derived from the DSC measurements, are depicted in Figure 3b.

3.2. OD Mixed Crystals: Crystallographic Study. OD FaceCentered Cubic Mixed Crystals. To obtain the lattice parameters of the OD FCC mixed crystals, Lindemann capillaries were cooled to $243.2 \mathrm{~K}$, the temperature at which they are stable or they can be kept metastable for X ray measurements (for higher compositions that 0.80 ).

Figure 5a displays the continuous variation of the FCC lattice parameter over the whole concentration range at $243.2 \mathrm{~K}$. This demonstrates the isomorphism relationship between the stable FCC phases of $\left(\mathrm{CH}_{3}\right)_{3} \mathrm{CBr}$ and $\mathrm{Cl}_{3} \mathrm{CBr}$.

OD Rhombohedral Mixed Crystals. For OD R mixed crystals, a similar procedure was used. Lindemann capillaries were slowly cooled to $215.2 \mathrm{~K}$. At this temperature, OD R mixed crystals are stable from $X=0$ to about 0.45 , whereas for mole fractions higher
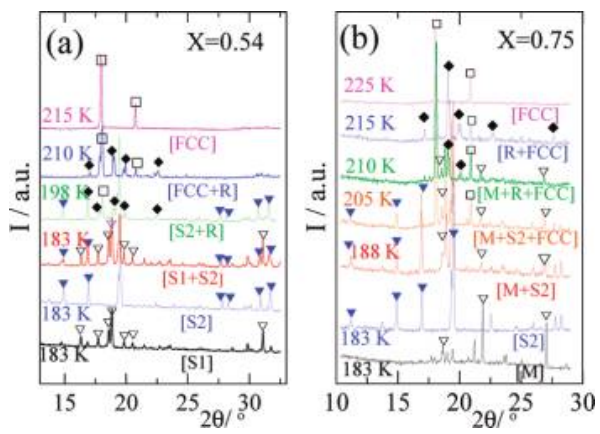

Figure 4. $\mathrm{X}$ ray diffraction patterns as a function of temperature for $X=0.54$ (a) and $X=0.75$ (b) samples. The two bottom patterns in each figure correspond to the single phases involved at $183 \mathrm{~K}$ for the S1 and S2 complexes. Symbols point to characteristic Bragg reflections to make easy the identification of coexisting phases: empty triangles. $\mathrm{S} 1$, $\left(\mathrm{CH}_{3}\right)_{3} \mathrm{CBr}: \mathrm{Cl}_{3} \mathrm{CBr}$ complex (left panel) or $\mathrm{M}\left(\mathrm{P}_{1} / n\right)$ (right panel); filled blue triangles, $\mathrm{S} 2$, $\left(\mathrm{CH}_{3}\right)_{3} \mathrm{CBr}_{2} 2 \mathrm{Cl}_{3} \mathrm{CBr}$ complex; filled diamonds, OD R, rhombohedral phase; empty squares, OD FCC, face centered cubic phase. Patterns for which three phases are coexisting (only possible for an invariant) were recorded during the transformations and are shown to help the reader follow the phase sequence.

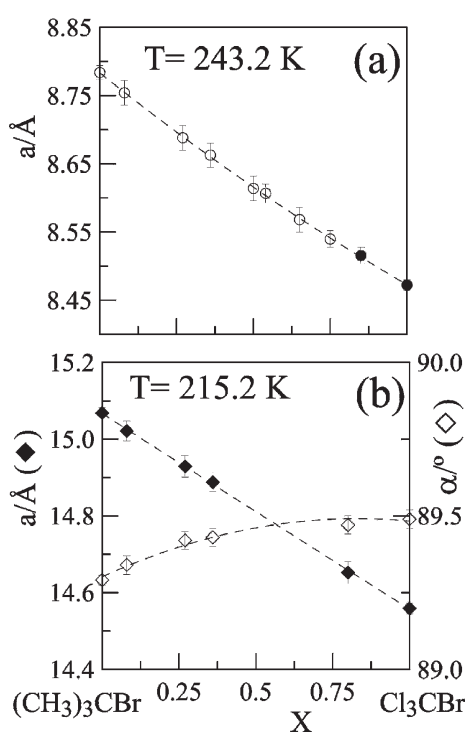

Figure 5. Lattice parameters $a$ for the OD FCC mixed crystals at 243.2 $\mathrm{K}(\mathrm{a})$ and $a$ and $\alpha$ for the R mixed crystals at $215.2 \mathrm{~K}$ (b) as a function of the mole fraction. Filled circles correspond to supercooled FCC mixed crystals.

than about 0.80 they were found to be persistent enough for the lattice parameters to be determined. Figure $5 \mathrm{~b}$ shows the determined lattice parameters as a function of the mole fraction. The continuity of the lattice parameter variation vs concentration indicates the same nature of such a mixed crystal for high and low concentration regions and that the lack of continuous OD $\mathrm{R}$ mixed crystals for the whole concentration range is due to the crossing of two phase, low temperature equilibria with the $[\mathrm{R}+$ FCC] two phase equilibrium. For short, both OD R phases are also linked by an isomorphism relationship. Such a result reinforces and makes sense of the continuous variation of the enthalpy change against composition for the R to FCC transition (see Figure 3b). 


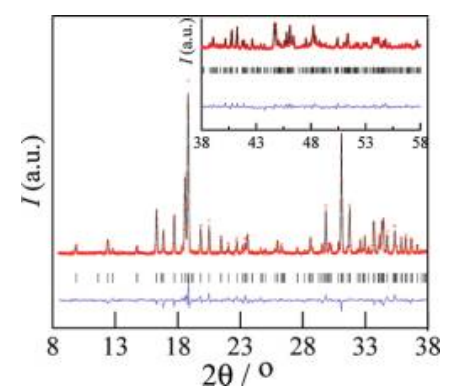

Figure 6. Final Rietveld refinement plot of the monoclinic $\left(P 2_{1} / c, Z=4\right)$ phase of the $\left(\mathrm{CH}_{3}\right)_{3} \mathrm{CBr}: \mathrm{Cl}_{3} \mathrm{CBr}$ complex (at $180 \mathrm{~K}$ ) showing the experimental (red circles) and calculated (black line) diffraction patterns and the difference profile (blue line). Vertical bars indicate the calculated Bragg positions. Inset corresponds to the scale for the data with $2 \theta>38^{\circ}$.

3.3. Low-Temperature Complexes. The lattice parameters and space groups of the complexes were obtained from long time acquisition $\mathrm{X}$ ray powder diffraction patterns at $180 \mathrm{~K}$ after $12 \mathrm{~h}$ annealing, using X Cell software ${ }^{54}$ available in the module Powder Indexing of Material Studio package. ${ }^{53}$ At this stage the number of molecules in the unit lattice $(Z)$ was calculated by assuming a density close to that of pure compounds. The cell parameters and space group compatible with the experimental $\mathrm{X}$ ray diffraction pattern were initially determined using a Pawley profile fitting procedure. ${ }^{55}$ By means of Pawley refinement minimizing the weighted $\mathrm{R}$ factor $\left(R_{\mathrm{wp}}\right.$, describing the agree ment between the experimental pattern and the simulated one), the indexing result was confirmed. The $2 \theta$ zero correction and the peak width asymmetry parameters were simultaneously determined. In addition, the analysis of the systematic absences made it possible to determine the possible space groups.

To fully characterize the structure of the low temperature complexes, the molecular structures as rigid bodies previously used for low temperature phases of pure compounds $\mathrm{Cl}_{3} \mathrm{CBr}$ and $\left(\mathrm{CH}_{3}\right)_{3} \mathrm{CBr}$ were taken. ${ }^{32,38,49}$ It is noteworthy that for the former molecule it was assumed that the fractional occupancies of the halogen sites were set as 0.25 and 0.75 for $\mathrm{Br}$ and $\mathrm{Cl}$ atoms, respectively, and thus the rigid body entity represents a pseudo molecule with tetrahedral symmetry in which overlapping $\mathrm{Br}$ and $\mathrm{Cl}$ atoms are located at 1.939 and $1.772 \AA$ from the central carbon atom $\mathrm{C}$.

Working within the constraints of rigid molecules, the $Z$ pseudo molecular entities forming the complexes, $\left(\mathrm{CH}_{3}\right)_{3} \mathrm{CBr}$ and $\mathrm{Cl}_{3} \mathrm{CBr}$, and $\left(\mathrm{CH}_{3}\right)_{3} \mathrm{CBr}$ and $2 \mathrm{Cl}_{3} \mathrm{CBr}$ for the $1: 1$ and $1: 2$ complexes, respectively, were placed in the unit lattice with the corresponding rotational and translational degrees of freedom to be refined by means of the Powder Solve program. This means that 12 parameters for the $1: 1$ complex and 18 for the $1: 2 \mathrm{com}$ plexes, in addition to the four preferred orientation parameters according to the March-Dollase function, ${ }^{56,57}$ were obtained. The fitting procedure by Powder Solve coherently succeeded and confirmed the space groups previously quoted by the systematic extinctions of the initial indexing performed by the Powder Indexing module.

Finally, within the rigid body constraint, the structures of the complexes were submitted to a Rietveld refinement, and all the parameters were left free again. For this last procedure, preferred orientation corrections were fitted according to the RietveldToraya parameters function. ${ }^{57,58}$ The following sections detail the structural characteristics of each complex.
Table 2. Results from the Rietveld Refinement of $\left(\mathrm{CH}_{3}\right)_{3} \mathrm{CBr}: \mathrm{Cl}_{3} \mathrm{CBr}$ and $\left(\mathrm{CH}_{3}\right)_{3} \mathrm{CBr}: 2 \mathrm{Cl}_{3} \mathrm{CBr}$ Complexes at $180 \mathrm{~K}$

\begin{tabular}{|c|c|c|}
\hline \multicolumn{3}{|c|}{$R_{\mathrm{wp}}=\left[\left[\sum w_{i} \mid c Y^{\operatorname{sim}}\left(2 \theta_{i}\right)-I^{\exp }\left(2 \theta_{i}\right)\right.\right.$} \\
\hline parameter & $\left(\mathrm{CH}_{3}\right)_{3} \mathrm{CBr}: \mathrm{Cl}_{3} \mathrm{CBr}$ & $\left(\mathrm{CH}_{3}\right)_{3} \mathrm{CBr}: 2 \mathrm{Cl}_{3} \mathrm{CBr}$ \\
\hline $2 \theta$-angular range & $8-70$ & $5-70$ \\
\hline $2 \theta$-shift (zero correction) & $0.00597 \pm 0.00071$ & $0.00734 \pm 0.00082$ \\
\hline \multicolumn{3}{|l|}{ Profile Parameters } \\
\hline $\mathrm{Na}$ & $0.355 \pm 0.042$ & $0.0787 \pm 0.0440$ \\
\hline $\mathrm{Nb}$ & $-0.0017 \pm 0.0015$ & $0.0097 \pm 0.0016$ \\
\hline space group & $P 2_{1} / c$ & $\mathrm{P}_{3}$ \\
\hline$Z\left(Z^{\prime}\right)$ & $4(1)$ & $6(1)$ \\
\hline \multicolumn{3}{|l|}{ Lattice Parameters } \\
\hline$a / \AA$ & $10.2032 \pm 0.0003$ & $18.1259 \pm 0.0006$ \\
\hline$b / \AA$ & $10.8651 \pm 0.0004$ & $18.1259 \pm 0.0006$ \\
\hline$c / \AA ̊$ & $12.1146 \pm 0.0004$ & $9.1535 \pm 0.0004$ \\
\hline$\alpha /^{\circ}$ & 90 & 90 \\
\hline$\beta /^{\circ}$ & $118.747 \pm 0.002$ & 90 \\
\hline$\gamma /{ }^{\circ}$ & 90 & 120 \\
\hline \multicolumn{3}{|l|}{ Reliability Parameters } \\
\hline$R_{\mathrm{wp}}$ & $18.55 \%(5.23 \% \mathrm{wbg})$ & $\begin{array}{l}19.71 \% \\
\quad(4.87 \% \mathrm{wbg})\end{array}$ \\
\hline$R_{\mathrm{p}}$ & $3.88 \%$ & $3.24 \%$ \\
\hline \multicolumn{3}{|l|}{ Peak Width Parameters } \\
\hline$u$ & $0.0775 \pm 0.0083$ & $0.0184 \pm 0.0085$ \\
\hline$v$ & $-0.0512 \pm 0.0049$ & $-0.0099 \pm 0.0048$ \\
\hline$w$ & $0.0160 \pm 0.0008$ & $0.0095 \pm 0.0007$ \\
\hline $\begin{array}{l}\text { overall isotropic temperature } \\
\text { factor, } U / \AA^{2}\end{array}$ & $0.0200 \pm 0.0011$ & $0.0651 \pm 0.0014$ \\
\hline \multicolumn{3}{|l|}{$\begin{array}{l}\text { Preferred Orientation } \\
\text { (Rietveld-Toraya Function) }\end{array}$} \\
\hline$a^{*}$ & 0.4045 & 0.4783 \\
\hline$b^{*}$ & 0.4594 & 0.4783 \\
\hline$c^{*}$ & 0.7908 & 0.7366 \\
\hline G1 & 0.4886 & 0.8254 \\
\hline G2 & 0.7242 & 0.9518 \\
\hline
\end{tabular}

3.3.1. $\left(\mathrm{CH}_{3}\right)_{3} \mathrm{CBr}: \mathrm{Cl}_{3} \mathrm{CBr}$ Complex. The experimentally recorded and final calculated profiles of the $\left(\mathrm{CH}_{3}\right)_{3} \mathrm{CBr}: \mathrm{Cl}_{3} \mathrm{CBr}$ complex are shown in Figure 6 together with the difference plot between them. The parameters of the monoclinic lattice (space group $P 2_{1} / c$ ) refined according to the described procedure are collected in Table 2, and the coordinates of the atoms of the asymmetric unit $\left(Z^{\prime}=1\right)$ are gathered in Table 3.

The asymmetric unit structure of the $\left(\mathrm{CH}_{3}\right)_{3} \mathrm{CBr}: \mathrm{Cl}_{3} \mathrm{CBr}$ complex comprises one pseudomolecular entity $\left(Z^{\prime}=1\right)$ formed by one molecule of each molecular species on a general position (Figure 7). Within this "ordered" structure with $Z=4$ molecules, 
Table 3. Fractional Atomic Coordinates of the $\left(\mathrm{CH}_{3}\right)_{3} \mathrm{CBr}$ : $\mathrm{Cl}_{3} \mathrm{CBr}$ Complex at $180 \mathrm{~K}$

\begin{tabular}{|c|c|c|c|c|c|}
\hline molecule & atom & $X$ & $Y$ & $Z$ & occupancy \\
\hline \multirow[t]{9}{*}{$\mathrm{Cl}_{3} \mathrm{CBr}$} & $\mathrm{C}$ & $0.0602(6)$ & $0.8478(4)$ & $0.3444(5)$ & 1 \\
\hline & $\mathrm{Cl}$ & $0.1006(8)$ & $1.0034(4)$ & $0.3927(7)$ & 0.75 \\
\hline & $\mathrm{Cl}$ & $0.0118(8)$ & $0.7681(4)$ & $0.4473(6)$ & 0.75 \\
\hline & $\mathrm{Cl}$ & $-0.0913(7)$ & $0.8415(6)$ & $0.1889(5)$ & 0.75 \\
\hline & $\mathrm{Cl}$ & $0.2195(7)$ & $0.7781(4)$ & $0.3486(7)$ & 0.75 \\
\hline & $\mathrm{Br}$ & $0.1045(8)$ & $1.0181(4)$ & $0.3972(7)$ & 0.25 \\
\hline & $\mathrm{Br}$ & $0.2346(7)$ & $0.7715(5)$ & $0.3490(7)$ & 0.25 \\
\hline & $\mathrm{Br}$ & $0.0072(8)$ & $0.7606(5)$ & $0.4571(5)$ & 0.25 \\
\hline & $\mathrm{Br}$ & $-0.1056(7)$ & $0.8409(6)$ & $0.1742(5)$ & 0.25 \\
\hline \multirow{14}{*}{$\left(\mathrm{CH}_{3}\right)_{3} \mathrm{CBr}$} & $\mathrm{C}$ & $0.5477(6)$ & $0.9363(8)$ & $0.8056(9)$ & 1 \\
\hline & $\mathrm{C}$ & $0.6727(17)$ & $1.0300(11)$ & $0.8772(15)$ & 1 \\
\hline & $\mathrm{C}$ & $0.3953(14)$ & $0.9903(16)$ & $0.7754(23)$ & 1 \\
\hline & $\mathrm{C}$ & $0.5481(25)$ & $0.8946(15)$ & $0.6849(11)$ & 1 \\
\hline & $\mathrm{H}$ & $0.6755(35)$ & $1.0592(9)$ & $0.9654(16)$ & 1 \\
\hline & $\mathrm{H}$ & $0.7833(10)$ & $0.9916(20)$ & $0.9016(22)$ & 1 \\
\hline & $\mathrm{H}$ & $0.6566(19)$ & $1.1131(13)$ & $0.8199(19)$ & 1 \\
\hline & $\mathrm{H}$ & $0.3046(6)$ & $0.9231(23)$ & $0.7259(26)$ & 1 \\
\hline & $\mathrm{H}$ & $0.3925(32)$ & $1.0186(18)$ & $0.8616(30)$ & 1 \\
\hline & $\mathrm{H}$ & $0.3694(16)$ & $1.0720(18)$ & $0.7146(26)$ & 1 \\
\hline & $\mathrm{H}$ & $0.6562(34)$ & $0.8535(21)$ & $0.7054(3)$ & 1 \\
\hline & $\mathrm{H}$ & $0.4605(36)$ & $0.8255(18)$ & $0.6336(6)$ & 1 \\
\hline & $\mathrm{H}$ & $0.5276(25)$ & $0.9729(20)$ & $0.6208(14)$ & 1 \\
\hline & $\mathrm{Br}$ & $0.5845(6)$ & $0.7928(5)$ & $0.9131(5)$ & 1 \\
\hline
\end{tabular}

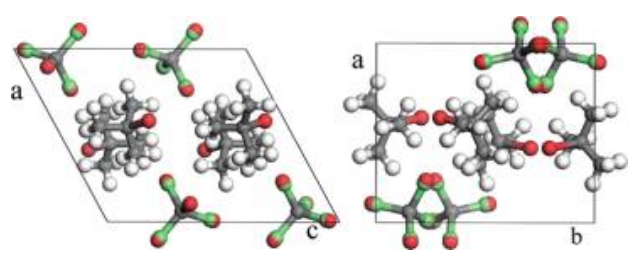

Figure 7. Projection of the $P 2_{1} / c$ monoclinic structure of the $\left(\mathrm{CH}_{3}\right)_{3} \mathrm{CBr}: \mathrm{Cl}_{3} \mathrm{CBr}$ complex on the (OkO) (left panel) and (OOl) (right panel) crystallographic planes.

the $\mathrm{Cl}_{3} \mathrm{CBr}$ entity of the asymmetric unit was assumed to be disordered so that sites have fractional occupancies of 0.25 and 0.75 for $\mathrm{Br}$ and $\mathrm{Cl}$ atoms, in the same way that it occurs for the low temperature phase of $\mathrm{Cl}_{3} \mathrm{CBr}$ and $\mathrm{Cl}_{2} \mathrm{CBr}_{2}$ compounds. Attempts to order the $\mathrm{Br}$ and $\mathrm{Cl}$ atoms of the $\mathrm{Cl}_{3} \mathrm{CBr}$ entity by fitting the fractional occupancies of the $\mathrm{Br}$ and $\mathrm{Cl}$ sites did not succeed, confirming the statistical disorder.

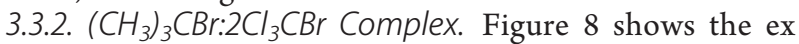
perimental and calculated profiles together with the difference plot between them for the $\left(\mathrm{CH}_{3}\right)_{3} \mathrm{CBr}: 2 \mathrm{Cl}_{3} \mathrm{CBr}$ complex at $180 \mathrm{~K}$. The refined parameters of the hexagonal lattice (space group $\mathrm{P}_{3}$ ) are gathered in Table 2 , and the coordinates of the atoms of the asymmetric unit $\left(Z^{\prime}=1\right)$ are summarized in Table 4.

For this complex, the asymmetric unit comprises one pseu domolecule formed by one $\left(\mathrm{CH}_{3}\right)_{3} \mathrm{CBr}$ molecule and two $\mathrm{Cl}_{3} \mathrm{CBr}$ molecules, i.e., $Z^{\prime}=1$. As for the previous complex, $\mathrm{Br}$ and $\mathrm{Cl}$ atoms occupy sites with fractional occupancies of 0.25 and 0.75 , respectively, making evident also the statistical disordered character of the structure (Figure 9).

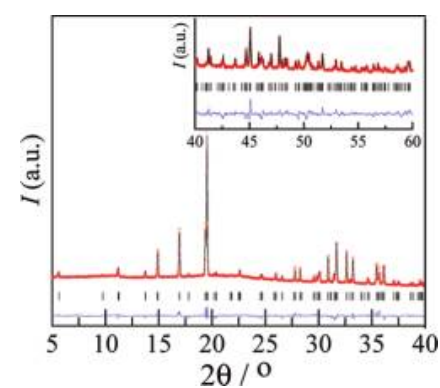

Figure 8. Final Rietveld refinement plot of hexagonal $\left(\mathrm{P}_{3}, Z=6\right)$ phase of $\left(\mathrm{CH}_{3}\right)_{3} \mathrm{CBr}: 2 \mathrm{Cl}_{3} \mathrm{CBr}$ complex (at $180 \mathrm{~K}$ ) showing the experimental (red circles), calculated (black line) diffraction patterns and the difference profile (blue line). Vertical bars indicate the calculated Bragg positions. Inset corresponds to the scale for the data with $2 \theta>40^{\circ}$.

3.4. Thermodynamic Assessment of the Phase Diagram. The thermodynamic assessment of the phase equilibria concern ing the OD and liquid phases has been carried out to derive the excess properties of such phases as well as to infer the truncated part (metastable) of the $[\mathrm{R}+\mathrm{FCC}]$ equilibrium.

The Gibbs energy for a mixture of $(1-X) \mathrm{mol}$ of pure component $\mathrm{A}$ and $X \mathrm{~mol}$ of pure component $\mathrm{B}$ displaying isomorphism in the $\alpha$ phase, i.e., the mixed crystal $\mathrm{A}_{1}{ }_{X} \mathrm{~B}_{X}$, is connected with the temperature and composition variables by

$$
G^{\alpha}(T, X)=(1-X) \mu_{\mathrm{A}}^{*, \alpha}+X \mu_{\mathrm{B}}^{*, \alpha}+R T \ln (X)+G^{\mathrm{E}, \alpha}(T, X)
$$

where $\mu_{\mathrm{i}}^{*}, \alpha(\mathrm{i}=\mathrm{A}, \mathrm{B})$ represents the molar Gibbs energies of pure components $\mathrm{A}$ and $\mathrm{B} ; \mathrm{R}$ is the gas constant; $\ln (X)=(1-$ $X) \ln (1-X)+X \ln X$; and $G^{\mathrm{E}, \alpha}(T, X)$ is the excess Gibbs energy that accounts for the deviation of the mixture in form $\alpha$ from ideal mixing behavior.

Thus, the two phase equilibrium region between two phases ( $\gamma$ and $\varphi$ ) is determined from the minimum Gibbs energy of the mixed crystal $\mathrm{A}_{1}{ }_{X} \mathrm{~B}_{X}$ at each temperature. An easy way to proceed, because of the lack of data on $\mu_{\mathrm{i}}{ }^{*},(i=\mathrm{A}, \mathrm{B}$ and $j=\gamma, \varphi)$ is the Equal Gibbs Curve (EGC) method. ${ }^{45}$ Within this approach, the difference between the Gibbs energies of phases $\gamma$ and $\varphi$ can be written as

$$
\begin{aligned}
\Delta G^{\gamma \rightarrow \varphi}(T, X)= & G^{\varphi}(T, X)-G^{\gamma}(T, X) \\
= & (1-X) \Delta \mu_{\mathrm{A}}^{\gamma}{ }^{\varphi}(T)+X \Delta \mu_{\mathrm{B}}^{\gamma \rightarrow \varphi}(T) \\
& +\Delta G^{\mathrm{E}, \gamma \rightarrow \varphi}(T, X)
\end{aligned}
$$

where $\Delta \mu_{\mathrm{A}}^{\gamma \rightarrow \varphi}=\mu_{\mathrm{B}}^{*, \varphi}-\mu_{\mathrm{B}}^{*, \gamma}(\mathrm{i}=\mathrm{A}, \mathrm{B})$ and $\Delta G^{\mathrm{E}, \gamma \rightarrow \varphi}(T, X)=G^{\mathrm{E}, \varphi}$ $(T, X)-G^{\mathrm{E}, \gamma}(T, X)$ is the excess Gibbs energy difference between $\gamma$ and $\varphi$ phases. Assuming that the specific heat does not change noticeably, $\Delta \mu_{\mathrm{A}}^{\gamma \rightarrow \varphi} \approx \Delta S_{\mathrm{i}}^{\gamma \rightarrow \varphi}\left(T_{\mathrm{i}}^{\gamma \rightarrow \varphi}-T\right)$, where $\Delta S_{\mathrm{i}}^{\gamma \rightarrow \varphi}$ is the entropy change for the transition from $\gamma$ to $\varphi$ at $T_{\mathrm{i}}^{\gamma \rightarrow \varphi}$, and the equation $\Delta G^{\gamma \rightarrow \varphi}\left(T_{\mathrm{EGC}}, X\right)=0$ provides a curve in the $T-X$ plane where $\gamma$ and $\varphi$ phases have equal values of the Gibbs energies (the EGC curve). From this equation, the EGC temperature can be obtained as

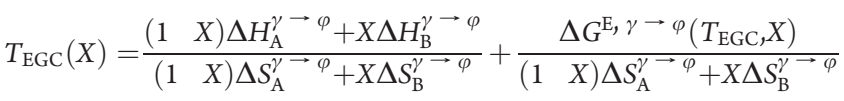


Table 4. Fractional Atomic Coordinates of the $\left(\mathrm{CH}_{3}\right)_{3} \mathrm{CBr}: 2 \mathrm{Cl}_{3} \mathrm{CBr}$ Complex at $180 \mathrm{~K}$

\begin{tabular}{|c|c|c|c|c|c|}
\hline molecule & atom & $X$ & $Y$ & $Z$ & occupancy \\
\hline \multirow[t]{9}{*}{$\mathrm{Cl}_{3} \mathrm{CBr}$} & $\mathrm{C}$ & $0.1024(6)$ & $0.8803(6)$ & $0.7034(13)$ & 1 \\
\hline & $\mathrm{Cl}$ & $0.1133(9)$ & $0.8060(6)$ & $0.8138(16)$ & 0.75 \\
\hline & $\mathrm{Cl}$ & $0.0670(10)$ & $0.8366(6)$ & $0.5270(14)$ & 0.75 \\
\hline & $\mathrm{Cl}$ & $0.0272(7)$ & $0.9032(9)$ & $0.7837(21)$ & 0.75 \\
\hline & $\mathrm{Cl}$ & $0.2022(6)$ & $0.9753(6)$ & $0.6892(14)$ & 0.75 \\
\hline & $\mathrm{Br}$ & $0.1144(9)$ & $0.7989(6)$ & $0.8242(16)$ & 0.25 \\
\hline & $\mathrm{Br}$ & $0.2117(6)$ & $0.9843(6)$ & $0.6878(14)$ & 0.25 \\
\hline & $\mathrm{Br}$ & $0.0636(11)$ & $0.8324(6)$ & $0.5103(14)$ & 0.25 \\
\hline & $\mathrm{Br}$ & $0.0201(7)$ & $0.9054(9)$ & $0.7913(23)$ & 0.25 \\
\hline \multirow[t]{9}{*}{$\mathrm{Cl}_{3} \mathrm{CBr}$} & $\mathrm{C}$ & $0.1251(5)$ & $0.5657(5)$ & $0.7049(14)$ & 1 \\
\hline & $\mathrm{Cl}$ & $0.0278(5)$ & $0.4675(6)$ & $0.7061(14)$ & 0.75 \\
\hline & $\mathrm{Cl}$ & $0.1328(6)$ & $0.6215(6)$ & $0.5415(14)$ & 0.75 \\
\hline & $\mathrm{Cl}$ & $0.1286(6)$ & $0.6277(6)$ & $0.8571(14)$ & 0.75 \\
\hline & $\mathrm{Cl}$ & $0.2114(5)$ & $0.5459(5)$ & $0.7148(20)$ & 0.75 \\
\hline & $\mathrm{Br}$ & $0.0186(5)$ & $0.4582(5)$ & $0.7062(14)$ & 0.25 \\
\hline & $\mathrm{Br}$ & $0.2196(5)$ & $0.5440(5)$ & $0.7157(20)$ & 0.25 \\
\hline & $\mathrm{Br}$ & $0.1335(6)$ & $0.6268(6)$ & $0.5260(14)$ & 0.25 \\
\hline & $\mathrm{Br}$ & $0.1289(6)$ & $0.6336(6)$ & $0.8715(14)$ & 0.25 \\
\hline \multirow[t]{14}{*}{$\left(\mathrm{CH}_{3}\right)_{3} \mathrm{CBr}$} & $\mathrm{C}$ & $0.1790(5)$ & $0.4521(6)$ & $0.1893(1)$ & 1 \\
\hline & $\mathrm{C}$ & $0.2269(5)$ & $0.5490(6)$ & $0.2103(37)$ & 1 \\
\hline & $\mathrm{C}$ & $0.1150(13)$ & $0.4079(17)$ & $0.3135(23)$ & 1 \\
\hline & $\mathrm{C}$ & $0.1339(15)$ & $0.4280(20)$ & $0.0408(14)$ & 1 \\
\hline & $\mathrm{H}$ & $0.2609(14)$ & $0.5673(17)$ & $0.3156(47)$ & 1 \\
\hline & $\mathrm{H}$ & $0.2742(8)$ & $0.5815(10)$ & $0.1238(57)$ & 1 \\
\hline & $\mathrm{H}$ & $0.1825(6)$ & $0.5739(7)$ & $0.2086(38)$ & 1 \\
\hline & $\mathrm{H}$ & $0.0812(12)$ & $0.3380(16)$ & $0.3013(48)$ & 1 \\
\hline & $\mathrm{H}$ & $0.1468(23)$ & $0.4234(31)$ & $0.4209(13)$ & 1 \\
\hline & $\mathrm{H}$ & $0.0667(14)$ & $0.4278(18)$ & $0.3154(23)$ & 1 \\
\hline & $\mathrm{H}$ & $0.1794(24)$ & $0.4582(31)$ & $-0.049(3)$ & 1 \\
\hline & $\mathrm{H}$ & $0.1005(18)$ & $0.3586(22)$ & $0.0230(40)$ & 1 \\
\hline & $\mathrm{H}$ & $0.0863(16)$ & $0.4487(20)$ & $0.0330(14)$ & 1 \\
\hline & $\mathrm{Br}$ & $0.2618(5)$ & $0.4134(6)$ & $0.1939(1)$ & 1 \\
\hline
\end{tabular}

where $\Delta H_{\mathrm{i}}^{\gamma \rightarrow \varphi}$ is the enthalpy change at the $\gamma \rightarrow \varphi$ transition for component $i$. It should be recalled that the first term of the right part in eq 3 is close to a straight line when enthalpy and entropy changes of the $\gamma \rightarrow \varphi$ transition for pure compounds A and B are similar, and thus, the deviation from such a behavior is mainly accounted for by the magnitude of the $\Delta G^{\mathrm{E}, \gamma \rightarrow \varphi}(T, X)$.

By using the experimental data of the $[\mathrm{FCC}+\mathrm{L}]$ and $[\mathrm{R}+$ FCC] equilibria, the procedure to obtain the excess Gibbs energy difference close to the EGC curve, $\Delta G^{\mathrm{E}, \gamma \rightarrow \varphi}\left(T_{\mathrm{EGC}}, X\right)$, has been performed by means of the LIQFIT software. ${ }^{59}$

In this framework, the description of each excess property (Gibbs energy, enthalpy, or entropy) is given by an $n$ parameter function in the form of a Redlich-Kister polynomial

$$
G^{\mathrm{E}, \alpha}(X)=X(1-X) \sum_{i=1}^{n} G_{i}(1-2 X)^{i} 1
$$

Finally, a temperature dependence of the excess Gibbs function can be obtained by the definition of the excess Gibbs energy written in terms of excess enthalpy $\left(H^{\mathrm{E}, \alpha}\right)$ and excess entropy $\left(S^{\mathrm{E}, \alpha}\right)$

$$
G^{\mathrm{E}, \alpha}(T, X)=H^{\mathrm{E}, \alpha}(X)-T S^{\mathrm{E}, \alpha}(X)
$$

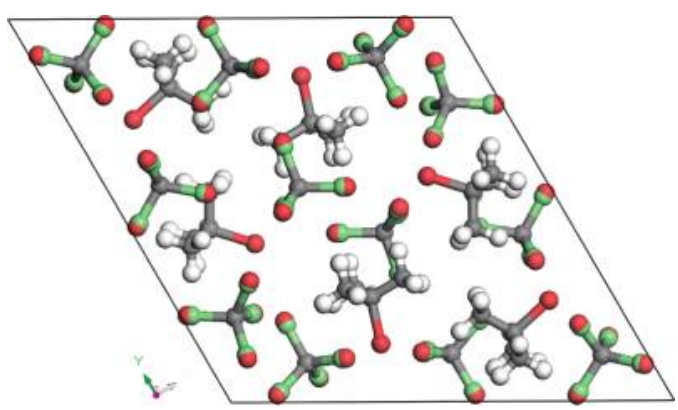

Figure 9. Projection of the $\mathrm{P}_{3}$ hexagonal structure of the $\left(\mathrm{CH}_{3}\right)_{3} \mathrm{CBr}: 2 \mathrm{Cl}_{3} \mathrm{CBr}$ complex viewed down $c$.

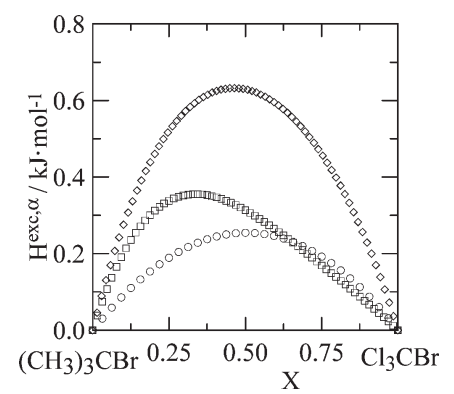

Figure 10. Excess enthalpy function for liquid (circles), OD FCC (squares), and OD R (diamonds) phases.

where both $H^{\mathrm{E}, \alpha}(X)$ and $S^{\mathrm{E}, \alpha}(X)$ are assumed to be temperature independent magnitudes within the temperature range studied.

The excess enthalpy of the OD phases can be obtained for $\mathrm{R}$ and FCC mixed crystals from their melting enthalpy changes and the data of the excess enthalpy of the liquid state (Figure 3). Thus, the enthalpy of a mixture in a $\gamma$ phase can be written as

$$
H^{\gamma}(X)=(1-X) H_{\mathrm{A}}^{\gamma}+X H_{\mathrm{B}}^{\gamma}+H^{\mathrm{E}, \gamma}(X)
$$

and then, the excess enthalpy of the OD phases can be calculated from

$$
H^{\mathrm{E}, \gamma}(X)=\Delta H_{\mathrm{id}}^{\gamma \rightarrow \varphi}(X)+H^{\mathrm{E}, \varphi}(X)-\Delta H^{\gamma \rightarrow \varphi}(X)
$$

where $\Delta H_{\mathrm{id}}^{\gamma \rightarrow \varphi}(X)$ is the enthalpy melting of an ideal mixture, $(1-X) \Delta H_{\mathrm{A}}^{\gamma \rightarrow \varphi}+X \Delta H_{\mathrm{B}}^{\gamma \rightarrow \varphi}$, and $\Delta H^{\gamma \rightarrow \varphi}(X)$ is the enthalpy effect of the mixed crystals at the $T_{\mathrm{i}}^{\gamma \rightarrow \varphi}$ transition.

Equation 7 is applied for $\varphi=\mathrm{L}$ and $\gamma=$ FCC and subsequently to $\varphi=$ FCC and $\gamma=\mathrm{R}$. Results for the excess enthalpies are reported in Figure 10, whereas the coefficients according to eq 4 are summarized in Table 5 .

\section{DISCUSSION}

The analysis of thermodynamic mixing data corresponding to structurally and chemically similar compounds leads to an understanding of the influence of the different factors on the formation of continuous mixed crystals. In addition, the existence of $\mathrm{OD}$ and low temperature ordered phases for the involved compounds may help to rationalize the play of orientational disorder into the intermolecular interactions.

Two competing factors ruling the formation of mixed crystals are known to be distinguished: (i) the size and shape of the mole cules and the unit cell dimensions, i.e., the steric or geometric 
Table 5. Redlich-Kister Polynomial for the Excess Enthalpy (in $\mathrm{J} \cdot \mathrm{mol}^{1}$ ) of the Liquid [L] State and the OD Face Centered Cubic [FCC] and Rhombohedral [R] Mixed Crys tals and the Excess Gibbs Difference (in $\mathrm{J} \cdot \mathrm{mol}^{\mathbf{1}}$ ) between $[\mathrm{L}]$ and $[\mathrm{FCC}]$ and $[\mathrm{FCC}]$ and $[\mathrm{R}]$

\begin{tabular}{|c|c|c|c|c|}
\hline phase & $\mathrm{H}_{1}$ & & $\mathrm{H}_{2}$ & $\mathrm{H}_{3}$ \\
\hline$[\mathrm{L}]$ & 1017 & & -15.5 & - \\
\hline$[\mathrm{FCC}]$ & 1256 & & 900 & 393 \\
\hline$[\mathrm{R}]$ & 2517 & & 322 & 393 \\
\hline equilibrium & $\Delta G_{1}^{\gamma \rightarrow \varphi}$ & $\Delta G_{2}^{\gamma \rightarrow \varphi}$ & $\Delta G_{3}^{\gamma} \rightarrow \varphi$ & $\Delta G_{4}^{\gamma \rightarrow} \rightarrow$ \\
\hline$\gamma=\mathrm{L}, \varphi=\mathrm{FCC}$ & -161.5 & -122.5 & -60 & \\
\hline$\gamma=\mathrm{FCC}, \varphi=\mathrm{R}$ & -300 & 650 & 605 & -750 \\
\hline
\end{tabular}

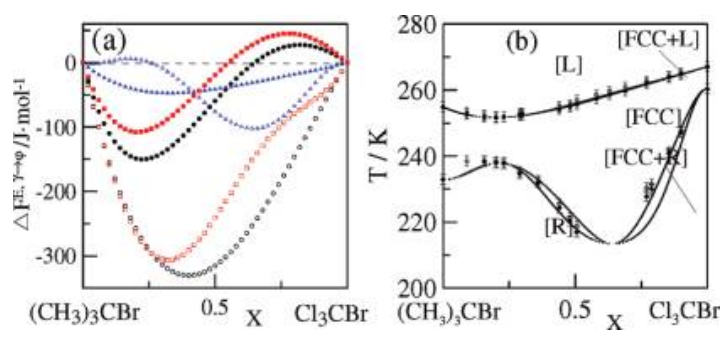

Figure 11. (a) Excess differences of the thermodynamic properties (enthalpy, $\Delta H^{\mathrm{E}, \gamma \rightarrow \varphi}$, black circles; Gibbs energy, $\Delta G^{\mathrm{E}, \gamma \rightarrow \varphi}$, blue trian gles; and entropic term, $T \Delta S^{\mathrm{E}, \gamma \rightarrow \varphi}$, red squares) for the R FCC phases, $\gamma=\mathrm{R}, \varphi=$ FCC (empty symbols) and for the FCC L phases, $\gamma=$ FCC, $\varphi=\mathrm{L}$ (full symbols). (b) Melting $([\mathrm{FCC}+\mathrm{L}])$ and $[\mathrm{R}+$ FCC $]$ equilibria calculated from the thermodynamic assessment with the experimental points.

conditions which define the so called geometric mismatch, and (ii) the role of the crossed intermolecular interactions in the mixed crystal structures.

In general, due to the mismatch factor, the mean of the attraction between molecules of different species $\mathrm{AB}$ (crossed) is weaker than the average of those of the same species, $\mathrm{AA}$ and $\mathrm{BB}$, in such a way that it translates to a net repulsion, i.e., a positive effect on the heat of mixing or, in terms of a thermo dynamic function, a positive excess enthalpy. As can be seen in Figure 10, this is the case for the liquid and OD R and FCC phases. Figure 11a shows the excess differences for the thermo dynamic properties, enthalpy, Gibbs energy, and the entropic term, the last one calculated by means of eq 5 . As for the $[\mathrm{FCC}+\mathrm{L}]$ equilibrium, it can be seen for the whole composition range that the excess Gibbs energy is negative and, as can also be easily seen by eq 3 , gives rise to a diminution of the stability temperature domain of the FCC phase, in particular to a minimum. As far as the $[\mathrm{R}+\mathrm{FCC}]$ equilibrium is concerned, in spite of the positive excess enthalpy of the OD R mixed crystals (see Figure 10), the entropic term $\left(T \Delta S^{\mathrm{E}, \mathrm{R} \rightarrow \mathrm{FCC}}(X)\right)$ contributes to the excess Gibbs energy in such a way that a maximum $(X \approx 0.22)$ and a minimum $(X \approx 0.65)$ appear giving rise to the same features in the $[\mathrm{R}+$ FCC] equilibrium (Figure 11b). In addition, it is worth noting that the obtained excess properties describe quite well a continuous $[\mathrm{R}+\mathrm{FCC}]$ equilibrium, which proves the existence of the isomor phism relationship between OD $\mathrm{R}$ phases of both components. The reason for the truncation of such equilibrium is the appearance of low temperature equilibria which intersect the stability domain of the OD R phase around $X \approx 0.66$, in which a complex is formed.
The existence of OD mixed crystals for the whole composi tion range between isomorphous phases is a common experi mental finding and has been explained by the easiness to simulate the symmetry elements of the orientationally disor dered host lattice for the guest molecule due to the existence of a large number of possible energetically feasible orientations, whereas the shape of the involved molecules is a physical misleading factor due to the pseudospherical appearance of the rotating molecules. A detailed discussion of these factors can be found in refs 46 and 47 .

Relating the low temperature domain of the phase diagram, an enormous complexity appears due to the existence of two complexes. It must be born in mind that the intermolecular interactions in this kind of compound are of van der Waals dispersion and dipole-dipole types and that the existence of complexes can be only understood by the appearance of an additional net attraction coming from an increase of the polarization of the molecules. On these grounds, a relevant parameter to account for is the intermolecular distances be tween halogen and methyl entities of first neighbor molecules. ${ }^{44}$ As nicely established in the work of Calvet et al. ${ }^{44}$ for a large number of molecular compounds in which the halogen and methyl group are involved, the comparison between the fre quency distributions of the shortest intermolecular contacts between $\mathrm{CH}_{3} \cdots \mathrm{CH}_{3}, \mathrm{Br} \cdot \cdots \mathrm{Br}$, and $\mathrm{CH}_{3} \cdots \mathrm{Br}$ reveals that the last distribution has a more pronounced peak than those of $\mathrm{CH}_{3} \cdots \mathrm{CH}_{3}$ and $\mathrm{Br} \cdots \mathrm{Br}$. The authors conclude that the $\mathrm{CH}_{3} \cdots \mathrm{X}$ (halogen) interaction is stronger than the average of the $\mathrm{CH}_{3} \cdots \mathrm{CH}_{3}$ and $\mathrm{X} \cdots \mathrm{X}$ interactions.

In the present case, a parallel quantitative analysis cannot be performed due to the statistical disorder in the $\mathrm{Cl}_{3} \mathrm{CBr}$ com pound which is also mimicked in both complexes. Such a stati stical disorder between $\mathrm{Cl}$ and $\mathrm{Br}$ atoms makes meaningless the halogen-halogen distances from a "real" description of the shortest contacts. A speaking example of this experimental fact is revealed by the $\mathrm{Br} \cdots \mathrm{Br}$ intermolecular distance within the low temperature structure of $\mathrm{Cl}_{3} \mathrm{CBr}$, for which values of 3.575 and $3.740 \AA$, shorter than the van der Waals diameter of the $\mathrm{Br}$ atom, are found. ${ }^{38}$ As for the $\left(\mathrm{CH}_{3}\right)_{3} \mathrm{CBr}$ orthorhombic low temperature (full) ordered phase, the shortest intermolecular $\mathrm{Br} \cdot \mathrm{CH}_{3}$ distances are 3.599, 3.782, 3.851, and 3.861 $\AA$. In spite of the statistical disorder of the halogen sites in both complexes, and assuming that at present the crystallographic tools are the best to describe the real microscopic ordered space, the same analysis has been performed for both complexes. Within this framework, the shortest intermolecular $\mathrm{Br} \cdot \mathrm{CH}_{3}$ distances are 3.601, 3.766, 3.804, and 3.829 A for the 1:1 monoclinic complex and $3.472,3.524,3.898$, and $3.948 \AA$ for the $1: 2$ hexagonal complex. For the former, the first shortest distance is similar to that of the orthorhombic phase of $\left(\mathrm{CH}_{3}\right)_{3} \mathrm{CBr}$, whereas the next three shortest distances are relatively smaller. Worth noting are the values for the 1:2 complex, for which the two first shortest $\mathrm{Br} \cdot \mathrm{CH}_{3}$ distances are remarkably smaller than those of the pure compound.

This experimental evidence means that the intermolecular interactions $\mathrm{CH}_{3} \cdots \mathrm{X}$ (halogen) are stronger within the com plexes than within the pure compound, giving strong support to the arguments and facts provided by the work of Calvet et al. ${ }^{44}$ concerning the methyl-halogen particular interaction.

Nevertheless, it should be strengthened that this increase of intermolecular interactions evidenced by the shortening of the distances between first neighbors is limited to a short range and 
does not translate into an increase of the packing coefficient (or density), which is a macroscopic magnitude. At $180 \mathrm{~K}$, the packing coefficient for both pure compounds, $\mathrm{Cl}_{3} \mathrm{CBr}$ and $\left(\mathrm{CH}_{3}\right)_{3} \mathrm{CBr}$, is 0.684 and 0.644 , respectively, whereas for the $1: 1$ and $1: 2$ complexes it is 0.650 and 0.658 , respectively. As the data reveal, packing coefficients of complexes are below those obtained by a linear combination (0.664 and 0.670 , for $1: 1$ and $1: 2$ complexes, respectively) of the coefficients of the pure compounds.

Finally, we would like to mention that formation of complexes between organic compounds has been reported when highly fluorinated compounds are mixed with aromatic hydrocarbons due to their availability of specific attractive interactions such as charge transfer and quadrupole-quadrupole interactions. ${ }^{60} \quad 63$ For most of these cases, it has been demonstrated that the electrostatic origin of the attractive interaction remains in the liquid state through molecular associations which give rise to strong negative excess properties in the liquid state. ${ }^{62,64} 66$ Nevertheless, it should be strengthened that the formation of complexes does not require the existence of negative excess enthalpy accounting for the intermolecular interactions in the liquid state, as reported in the present case.

\section{CONCLUSIONS}

The two component phase diagram $\left(\mathrm{CH}_{3}\right)_{3} \mathrm{CBr}+\mathrm{Cl}_{3} \mathrm{CBr}$ has been determined from the low temperature region involving orientationally ordered phases up to the liquid (L) state. Mixed crystals between the orientationally disordered face centered cubic (FCC) phases of both pure compounds are formed for the whole composition range, evidence of the isomorphism relationship between both. As for the orientationally disordered rhombohedral $(\mathrm{R})$ phase, the continuous formation of mixed crystals is truncated by the interference of the low temperature two phase equilibrium involving ordered phases with the $[\mathrm{R}+$ FCC] equilibrium. Nevertheless, the thermodynamic assessment of the $[\mathrm{FCC}+\mathrm{L}]$ and $[\mathrm{R}+\mathrm{FCC}]$ equilibria enables us to conclude the existence of an isomorphism relationship between both $\mathrm{R}$ phases. Of special relevance in this two component system is the maximum and minimum for the $[\mathrm{R}+\mathrm{FCC}]$ two phase equilibrium because there are very few systems showing a solidsolid equilibrium with such extremes. ${ }^{45}$ Similar behavior was recently found for the system $\mathrm{CCl}_{4}+\left(\mathrm{CH}_{3}\right)_{3} \mathrm{CBr}^{40}$ The analysis of the assessed excess properties of the OD R and FCC phases evidences the role played by the entropic term in the excess Gibbs energy, which counterbalances the positive excess enthalpy.

One additional striking feature of the reported two compo nent system concerns the existence of two complexes in the low temperature region. This experimental fact is explained in terms of the attractive interaction between unlike molecules within the complex coming from the particular interaction between halogen atoms and the methyl group.

The experimental evidence means that the intermolecular interactions $\mathrm{CH}_{3} \cdots \mathrm{X}$ (halogen) are stronger within the com plexes than within the pure compound, giving strong support to the arguments and facts provided by the work of Calvet et al. concerning the methyl-halogen particular interaction. ${ }^{44}$

\section{AUTHOR INFORMATION}

\section{Corresponding Author}

*Phone: +34 934016564. Fax +34 934011839. E mail: jose.luis.tamarit@upc.edu.

\section{ACKNOWLEDGMENT}

This work was supported by the Spanish Ministry of Science and Innovation (grant FIS2008 00837) and by the Catalan government (grant 2009SGR 1251).

\section{REFERENCES}

(1) Mansson, T.; Larsson, K. E. J. Chem. Phys. 1997, 67, 4996.

(2) Hasebe, T. Bull. Chem. Soc. Jpn. 1990, 2877.

(3) Richardson, R. M.; Taylor, P. Mol. Phys. 1984, 52, 525.

(4) Leadbetter, A. J.; Ward, R. C.; Richardson, R. M. J. Chem. Soc., Faraday Trans. 2 1985, 81, 1067.

(5) Kreul, H. G.; Hartmann, M.; Edelmann, R.; Würflinger, A. Ber. Bunsenges. Phys. Chem. 1989, 93, 612.

(6) Chen, J.; Bartell, L. S. J. Phys. Chem. 1993, 97, 10645.

(7) Ferrario, M.; Klein, M. L.; Lynden Bell, R. M.; McDonald, I. R. J. Chem. Soc., Faraday Trans. 2 1987, 83, 2097.

(8) Rey, R. J. Chem. Phys. 2007, 126, 164506.

(9) Rey, R. J. Chem. Phys. 2008, 129, 224509.

(10) Llanta, E.; Ando, K.; Rey, R. J. Phys. Chem. B 2001, 105, 7783.

(11) Rey, R.; Pardo, L. C.; Llanta, E.; Ando, K.; López, D. O.; Tamarit, J. Ll.; Barrio, M. J. Chem. Phys. 2000, 112, 7505.

(12) Pothoczki, S.; Temleitner, L; Jovari, P.; Kohara, S.; Pusztai, L. J. Chem. Phys. 2009, 130, 064503.

(13) Pardo, L. C.; Tamarit, J. Ll.; Veglio, N.; Bermejo, F. J.; Cuello, G. J. Phys. Rev. B 2007, 76, 134203.

(14) Pardo, L. C.; Veglio, N.; Bermejo, F. J.; Tamarit, J. Ll.; Cuello, G. J. Phys. Rev. B 2005, 72, 014206.

(15) Veglio, N.; Bermejo, F. J.; Pardo, L. C.; Tamarit, J. Ll.; Cuello, G. J. Phys. Rev. E 2005, 72, 031502.

(16) Silver, L.; Rudman, R. J. Phys. Chem. 1970, 74, 3134.

(17) Powers, R.; Rudman, R. J. Chem. Phys. 1980, 72, 1629.

(18) Kobashi, K.; Oguni, M. J. Phys. Chem. B 1999, 103, 7687.

(19) Zuriaga, M.; Pardo, L. C.; Lunkenheimer, P.; Tamarit, J. Ll.; Veglio, N.; Barrio, M.; Bermejo, F. J.; Loidl, A. Phys. Rev. Lett. 2009, 103, 075701.

(20) Temleitner, L.; Pusztai, L. Phys. Rev. B 2010, 81, 134101.

(21) Pothoczki, S.; Temleitner, L.; Pusztai, L. J. Chem. Phys. 2010, $132,164511$.

(22) Zielinski, P.; Fouret, R.; Foulon, R.; More, M. J. Chem. Phys. 1990, 93, 1948.

(23) Reuter, J.; Büsing, D.; Tamarit, J.Ll.; Würflinger, A. J. Mater. Chem. 1997, 7, 41.

(24) Dove, M. T.; Lynden Bell, R. M. J. Phys. C: Solid State Phys. 1986, 19, 3363.

(25) Miller, R. C.; Smyth, C. P. J. Chem. Phys. 1956, 24, 814.

(26) Ohta, T.; Yamamuro, O.; Matsuo, T. J. Phys. Chem. 1995, 99, 2403.

(27) Binbrek, O. S.; Lee Dadswell, S. E.; Torrie, B. H.; Powell, B. M. Mol. Phys. 1999, 96, 785.

(28) Rudman, R. J. Mol. Struct. 2001, 569, 157.

(29) Jenau, M.; Reuter, J.; Würflinger, A.; Tamarit, J.Ll. J. Chem. Soc., Faraday Trans. 1996, 92, 1899.

(30) Pardo, L. C.; Barrio, M.; Tamarit, J.Ll.; López, D. O.; Salud, J.; Negrier, P.; Mondieig, D. J. Phys. Chem. B 2001, 105, 10326.

(31) Pardo, L. C.; Barrio, M.; Tamarit, J.Ll.; López, D. O.; Salud, J.; Negrier, P.; Mondieig, D. Phys. Chem. Chem. Phys. 2001, 3, 2644.

(32) Negrier, P.; Barrio, M.; Tamarit, J. Ll.; Mondieig, D. Cryst. Growth Des. 2010, 10, 2793.

(33) Pardo, L. C.; Barrio, M.; Tamarit, J.Ll.; López, D. O.; Salud, J.; Negrier, P.; Mondieig, D. Chem. Phys. Lett. 1999, 308, 204.

(34) Pardo, L. C.; Barrio, M.; Tamarit, J. Ll.; López, D. O.; Salud, J.; Negrier, P.; Mondieig, D. Chem. Phys. Lett. 2000, 321, 438.

(35) Salud, J.; López, D. O.; Barrio, M.; Tamarit, J. Ll.; Oonk, H. A. J.; Haget, Y.; Negrier, P. J. Solid State Chem. 1997, 133, 536.

(36) Parsonage, N. G.; Stavely, L. A. K. Disorder in Crystals; Clarendon: Oxford, 1978. 
(37) Barrio, M.; Tamarit, J. Ll.; Negrier, P.; Pardo, L. C.; Veglio, N.; Mondieig, D. New J. Chem. 2008, 32, 232.

(38) Parat, B.; Pardo, L. C.; Barrio, M.; Tamarit, J. Ll.; Negrier, P.; Salud, J.; López, D. O.; Mondieig, D. Chem. Mater. 2005, 17, 3359.

(39) Tamarit, J.Ll.; Barrio, M.; Pardo, L. C.; Negrier, P.; Mondieig, D. J. Phys.: Condens. Matter 2008, 20, 244110.

(40) Barrio, M.; Pardo, L. C.; Tamarit, J. Ll.; Negrier, P.; Salud, J.; López, D. O.; Mondieig, D. J. Phys. Chem. B 2006, 110, 12096.

(41) Barrio, M.; Tamarit, J. Ll.; Céolin, R.; Pardo, L. C.; Negrier, P.; Mondieig, D. Chem. Phys. 2009, 358, 156.

(42) Barrio, M.; Pardo, L. C.; Tamarit, J. Ll.; Negrier, P.; López, D. O.; Salud, J.; Mondieig, D. J. Phys. Chem. B 2004, 108, 11089.

(43) Barrio, M.; de Oliveira, P.; Céolin, R.; López, D. O.; Tamarit, J. Ll. Chem. Mater. 2002, 14, 851.

(44) Calvet, T.; Cuevas Diarte, M. A.; Haget, Y.; Mondieig, D.; Kok, I. C.; Verdonk, M. L.; van Miltenburg, J. C.; Oonk, H. A. J. J. Chem. Phys. 1999, 110, 4841.

(45) Oonk, H. A. J. Phase Theory: The Thermodynamics of Hetereo geneous Equilibria; Elsevier Science Publishers: Amsterdam, 1981.

(46) Barrio, M.; López, D. O.; Tamarit, J. Ll.; Negrier, P.; Haget, Y. J. Mater. Chem. 1995, 5, 431.

(47) Barrio, M.; López, D. O.; Tamarit, J. Ll.; Negrier, P.; Haget., Y. J. Solid State Chem. 1996, 124, 29.

(48) Wenzel, U.; Schneider, G. M. Thermochim. Acta 1986, 109, 111.

(49) Negrier, P.; Tamarit, J. Ll.; Barrio, M.; Pardo, L. C.; Mondieig, D. Chem. Phys. 2007, 336, 150.

(50) Rute, M. A.; Salud, J.; Negrier, P.; López, D. O.; Tamarit, J. Ll.; Puertas, R.; Barrio, M.; Mondieig, D. J. Phys. Chem. B 2003, 107, 5914.

(51) Evain, M.; Deniard, P.; Jouanneaux, A.; Brec, R. J. Appl. Crystallogr. 1993, 26, 563.

(52) Engel, G. E.; Wilke, S.; Konig, O.; Harris, K. D. M.; Leusen,

F. J. J. J. Appl. Crystallogr. 1999, 32, 1169.

(53) MS Modeling (Material Studio), version 4.1: http://www.accelrys. com /mstudio/ms modeling (accessed February, 2010).

(54) Neumann, M. A. J. Appl. Crystallogr. 2003, 36, 356.

(55) Pawley, G. S. J. Appl. Crystallogr. 1981, 14, 357.

(56) Dollase, W. A. J. Appl. Crystallogr. 1986, 19, 267.

(57) Toraya, H.; Marumo, F. Miner. J. 1981, 10, 211.

(58) Rietveld, H. M. J. Appl. Crystallogr. 1969, 2, 65.

(59) Jacobs, M. H. G.; Oonk, H. A. J. LIQFIT, A Computer Program for the Thermodynamic Assessment of TX Liquidus or Solidus Data; Utrecht University: Utrecht, The Netherlands, 1990.

(60) Patrick, C. R.; Prosser, G. S. Nature 1960, 187, 1021.

(61) McLaughlin, E.; Messer, C. E. J. Chem. Soc. A 1966, 1106.

(62) Marbeuf, A.; Mondieig, D.; Metivaud, V.; Negrier, P.; Cuevas Diarte, M.; Haget, Y. Mol. Cryst. Liq. Cryst. 1997, 293, 309.

(63) Mikailitchenko, D.; Marbeuf, A.; Haget, Y.; Oonk, H. A. J. Mol. Cryst. Liq. Cryst. 1998, 319, 291.

(64) Fenby, D. V.; McLure, I. A.; Scott, R. L. J. Phys. Chem. 1966, 70, 602.

(65) Fenby, D. V.; Scott, R. L. J. Phys. Chem. 1967, 71, 4103.

(66) Andrews, A.; Morcom, K. W.; Duncam, W. A.; Swinton, F. L.; Pollock, J. M. J. Chem. Thermodyn. 1970, 2, 95. 